\title{
PRODUCTION FORECASTING AND EVALUATION OF INVESTMENTS USING ALLEN TWO-FACTOR PRODUCTION FUNCTION
}

\author{
Viktor Koval', Olha Slobodianiuk ${ }^{2}$ \\ Odessa Institute of Trade and Economics of Kyiv National University of Trade and Economics, Ukraine \\ Volodymyr Yankovyi ${ }^{3}$ \\ Odessa National Economic University, Ukraine
}

\begin{abstract}
The purpose of the article is to substantiate and systematize theoretical knowledge about Allen production function and it is an attempt to apply it in the tasks of modelling, analysis, and production forecasting at enterprises. Methodology. In the presented work, estimation's questions of unknown parameters of Allen function based on the least squares method and regression analysis on the basis of standard programs of the Excel are discussed; its belonging to neoclassical functions, as well as the most important economic and mathematical characteristics. In particular, in the framework of Allen production function, the formulas for average return of resources (capital productivity and productivity), marginal returns of resources, elasticity of output on factors need for productive resources, when there is a production output and one of the factors is given, also the replacement of resources (capital assets), the marginal rate of substitution of factors, the elasticity of replacement of resources (labour with capital). Results. Based on the assumption that Allen function belongs to the group of substitutional functions according to the equivalence principle, the formula of optimal capital formation is determined, which maximizes output at given total capital expenditures on the main production funds and labour remuneration (minimizes the total capital expenditures for a given volume of production). In addition, the calculation formulas for determining the maximum output (minimum total cost of capital) in terms of optimal capital stock are given. All the above indicators are summarized in the summary table of the main economic and mathematical characteristics of Allen production function. Practical implications. In the case when the model is based on empirical data that varies in time, for example, at one enterprise in a number of years, we are proposed to use the dynamic Allen production function, which explicitly includes the time factor. In both cases, the volume of the information base (sample size) is determined, which will ensure the representativeness of future conclusions regarding unknown parameters that are subject to evaluation. The article also considers Allen production function as an instrument for evaluating the economic efficiency of future investment in production in the usual and dynamic variants. Value/originality. The obtained theoretical and methodological aspects of Allen two-factor production function are illustrated in a practical example of construction, economic interpretation, and practical use of the model.
\end{abstract}

Key words: economic system, Allen production function, equimarginal principle, investments, dynamics.

JEL Classification: C61, C65, D20, D24

\section{Introduction}

The structural nature of factors, which influence the slowdown in the rate of return on investment and the changing conditions of the functioning of the economy, necessitates the improvement of its research methods on the basis of the development of constructing production functions' methods. For the simulation of production processes in the economy, the production functions of investment description are used, which as a factor of production affects dynamics of output.

The assessment of investment as an indicator of the state of production efficiency is one of the main

\footnotetext{
Corresponding author:

${ }^{1}$ Department of Applied Economics, Odessa Institute of Trade and Economics of Kyiv National University of Trade and Economics.

E-mail: victor-koval@ukr.net

${ }^{2}$ Department of Finance, Banking and Insurance, Odessa Institute of Trade and Economics of Kyiv National University of Trade and Economics.

E-mail: Slobodianiuk@gmail.com

${ }^{3}$ Department of Economy of Enterprise and Organization of Entrepreneurial Activity, Odessa National Economic University.

E-mail:vladimir_ya@ukr.net
} 
indicators determining the effectiveness of measures for modernization and restoration of fixed assets. That's why the use of production functions will allow assessing the impact of individual production factors on the efficiency of production.

Unlike the most popular economic researches of the Cobb-Douglas production functions and functions with constant substitution elasticity of resources, the practical application of Allen production function is quite rare in the national scientific literature devoted to mathematical and statistical modelling and forecasting.

Allen two-factor production function is described by a mathematical model:

$$
Y=A_{0} K L-A_{1} K^{2}-A_{2} L^{2},
$$

Allen two-factor production function describes the dependence of output $Y$ in value terms on the cost of the main productive funds $\mathrm{K}$ and the payment of labour $L$, in the economic literature can only be found that it has two properties:

1) growth rates of the marginal productivity of factors are constant;

2) function (1) is homogeneous.

The first property of Allen production function is easily verified if we will find the second partial derivatives of each factor:

$$
\frac{\partial^{2} Y}{\partial^{2} K}=-2 A_{1} ; \quad \frac{\partial^{2} Y}{\partial^{2} L}=-2 A_{2} .
$$

The second property is also no doubt. To check it, we increase each production factor by $\lambda$ times. Then the new output of $Y_{1}$ by formula (1) will increase $\lambda^{2}$ times:

$$
Y_{1}=A_{0} \lambda^{2} K L-A_{1} \lambda^{2} K^{2}-A_{2} \lambda^{2} L^{2}=\lambda^{2} Y,
$$

It is mean that Allen production function is a homogeneous function with a homogeneity coefficient 2.

In addition, it is known that provided $A_{1}, A_{2}>0$ the production function (1) is intended for a formal description of production processes, in which the excessive growth of any of the factors negatively affects the volume of output. Usually, such a feature is used to describe small-scale market and production systems with limited resources processing capabilities.

Today, this is all that can actually be learned about Allen production function, although, in our opinion, the role of this function is highly underestimated as, in the conditions of the permanent crisis of the domestic economy, this behaviour is typical for the production of most industrial enterprises.

\section{Analysis of recent research and publications}

The theory and practice of using two-factor production functions in the economy have been the subject of research by many foreign and domestic scientists for a hundred years.
Since the construction of production functions allows you to determine the impact of each resource on the result of production and provide a forecast for changes in production volume with changes in the volume of resources.

The most popular economic research of the production function is the Cobb-Douglas function (Cobb, 1928) for analysing the magnitude of capital and labour on the volume of production in the industry based on the definition of the optimum of the commodity producer in the classical and dynamic variants. The CobbDouglas function is used to describe the dependence of production on its production factors.

The works of the authors Griliches \& Mairesse (1995) and others are devoted to the analysis of the economy as a level of industries, and the level of the enterprise on the basis of the production function of Cobb-Douglas.

The question of the definition of essence and conditions for maximizing neoclassical production functions with the definition of the level of the optimal capital stock was considered in publications by Perloff (2014), Debertin (2012).

Debertin (2012) examines algebraic conditions for maximizing neoclassical production functions on the basis of multiplicative production models. However, in his work, he explores local extremes and maximum on the basis of saddle points of production functions, but without an assessment of the impact on the output of the assets' level in the framework of investigated production functions.

Chetyrkin \& Klas (1986) depicts the output function as a function of $Y=f(K, L)$, which reflects the dependence of productivity on factors including capital stock. Determination of capital stock's optimum at the enterprise is the receipt of a given volume of production on the basis of production functions' corresponding isoquant, and economic possibilities of the enterprise are given by isocost production functions.

In practice, other production functions are also used, in particular, Leontief functions, which are used to simulate deterministic production processes, which do not allow deviations from the established norms of resource use per unit of output.

Investigation of the model of the production process based on two-factor production functions according to Kleiner (1986) characterizes a stable quantitative dependence between the indicators of resources and output.

Among modern scholars should be noted Hrabovetskyi (2006), Pavelescu (2011), Lewin (2000), Mazzi and Lemoine (2010), Solow (1957), Shumska (2007a).

Among the authors who have recently been using production functions, generalized by the CE-function, it is necessary to note the work of Shumska (2007b). However, there is no systematic approach to the solution of the problem in the modern economic literature. The 
CES-function is the most common one and is used in the absence of complete information on the level of interchangeability of production factors and can, therefore, be used to model systems of any level.

Allen function is intended to describe production processes, in which excessive growth of one factor affects the volume of production.

The mention of the existence in the theory of Allen production functions can be found in the works of Borovskyi (2008), Shumska (2007b). But all of them are without exception limited to the statement of the above two properties of production functions (1), as well as an indication of the area of its possible use. And all authors give practically the same brief information. As for the methods of estimating the unknown parameters of Allen two-factor production functions A0, A1, A2, their economic interpretation, the membership of the production functions (1) to neoclassical functions, their more important economic and mathematical characteristics and other theoretical and practical issues, all of them were left out of the attention of specialists in the field of econometric modelling and forecasting.

\section{Setting targets}

The purpose of the study is to develop and systematize theoretical knowledge of Allen production function and attempt to apply it in the tasks of modelling, analysis, and production forecasting at enterprises.

\section{Analysis of the apparatus of the production function and the problem of constructing a model of economic growth}

Simulation of a dynamic production function. Let us start with methods of estimating unknown parameters of production function (1) $A_{0}, A_{1}, A_{2}$. Enter the following notation: $K^{2}=X ; L^{2}=Z ; K L=\sqrt{X Z}$. Then the expression (1) is represented as follows:

$$
Y=A_{0} \sqrt{X Z}-A_{1} X-A_{2} Z \text {. }
$$

Obviously, equation (4) is a simple linear function of variables $X, Z$ and $\sqrt{X Z}$, and estimation of unknown parameters $A_{0}, A_{1}, A_{2}$ is reduced to the use of the usual least squares method on the basis of standard regression analysis programs, for example, in the Excel, or in a program package STATISTICA. It is mean, there are no special problems: it is enough to calculate the variables according to empirical data $X, Z, \sqrt{X Z}$ and carry out a well-known procedure for evaluating regression coefficients. In this case, the accuracy of the constructed model is characterized by the magnitude of the determination coefficient $R^{2}\left(0 \leq R^{2} \leq 1\right)$.

Allen production function does not apply to neoclassical functions, since conditions $f(K, 0)=0$, $f(0, L)=0$ are not fulfilled:

$$
f(K, 0)=-A_{1} K^{2} ; f(0, L)=-A_{2} L^{2} \text {. }
$$

This means that when $A_{1}, A_{2}<0$ production function (1) involves production output $Y$ only at the expense of one production factor $K$ or $L$, that is, the elasticity of their replacement goes to infinity $\left(\sigma_{L K} \rightarrow \infty\right)$, which is characteristic of a linear function $Y-A_{3}=A_{0} K L+A_{1} K^{2}+A_{2} L^{2}$.

Consider the more important economic and mathematical characteristics of Allen production function.

1) average returns of the unit of each factor (return on capital and productivity):

$$
\begin{aligned}
& \frac{Y}{K}=\frac{A_{0} K L-A_{1} K^{2}-A_{2} L^{2}}{K}=A_{0} L-A_{1} K-A_{2} L\left(\frac{L}{K}\right), \\
& \frac{Y}{L}=\frac{A_{0} K L-A_{1} K^{2}-A_{2} L^{2}}{L}=A_{0} K-A_{1} K\left(\frac{K}{L}\right)-A_{2} L .
\end{aligned}
$$

2) the marginal productivity of capital $\left(M P_{K}\right)$ and marginal productivity of labour $\left(M P_{L}\right)$, which show how much output will increase $Y$ with an increase in the corresponding factor per unit:

$$
\begin{aligned}
& M P_{K}=\frac{\partial Y}{\partial K}=A_{0} L-2 A_{1} K ; \\
& M P_{L}=\frac{\partial Y}{\partial L}=A_{0} K-2 A_{2} L .
\end{aligned}
$$

3 ) product elasticity $Y$ by factors $K, L$, which shows how many percents changes the average output of products when the value of the corresponding factor is changed by one percent:

$$
\begin{aligned}
& E_{K}=\frac{\partial Y}{Y}: \frac{\partial K}{K}=\frac{\partial Y}{\partial K}: \frac{Y}{K}=\frac{A_{0} L-2 A_{1} K}{A_{0} L-A_{1} K-A_{2} L\left(\frac{L}{K}\right)}, \\
& E_{\mathrm{L}}=\frac{\partial Y}{Y}: \frac{\partial L}{L}=\frac{\partial Y}{\partial L}: \frac{Y}{L}=\frac{A_{0} K-2 A_{2} L}{A_{0} K-A_{1} K\left(\frac{K}{L}\right)-A_{2} L} .
\end{aligned}
$$

That is, the elasticity of output $Y$ by factors $K, L$ represents the ratio of the marginal impact and the average return of each factor.

4) the need for production factors when output $Y$ and one of the resources is given:

$$
\begin{aligned}
& K=f(Y, L)=\frac{-A_{0} L \pm \sqrt{D}}{2 A_{1}}, \text { de } D=\left(A_{0} L\right)^{2}-4 A_{1}\left(Y+A_{2} L^{2}\right) \\
& L=f(Y, L)=\frac{-A_{0} K \pm \sqrt{D}}{2 A_{2}}, \text { de } D=\left(A_{0} K\right)^{2}-4 A_{2}\left(Y+A_{1} K^{2}\right) .
\end{aligned}
$$

Here we mean that determinants of the corresponding square equations $D \geq 0$. If $D=0$ solutions (9) are simplified:

$$
K=f(Y, L)=-\frac{A_{0} L}{2 A_{1}}, \quad L=f(Y, K)=-\frac{A_{0} K}{2 A_{2}}
$$

and the need for resources does not depend on the volume of output.

5) replacement of factors (capital stock $F=\frac{K}{L}$ ) as the ratio of resources found on the basis of formulas (9) or (10).

6) marginal rate of substitution of factors as a ratio of marginal returns of production factors (7): 


$$
M R S_{L K}=\frac{M P_{L}}{M P_{K}}=\frac{A_{0} K-2 A_{2} L}{A_{0} L-2 A_{1} K}=\frac{A_{0} \frac{K}{L}-2 A_{2}}{A_{0}-2 A_{1} \frac{K}{L}}=\frac{A_{0} F-2 A_{2}}{A_{0}-2 A_{1} F} .
$$

Obviously, the condition must be fulfilled $A_{0} \neq 2 A_{1} F$, and capital stock $F$ is taken on average in the aggregate of observation levels.

7) the elasticity of the substitution of factors (labour by capital) taking into account the formula (11):

$$
\begin{aligned}
& \sigma_{L K}=\frac{\partial\left(\frac{K}{L}\right)}{\frac{K}{L}}: \frac{\partial\left(M R S_{L K}\right)}{M R S_{L K}}=\frac{\partial\left(\frac{K}{L}\right) M R S_{L K}}{\partial\left(M R S_{L K}\right) \frac{K}{L}}= \\
& =\frac{\left(A_{0} F-2 A_{2}\right)\left(A_{0}-2 A_{1} F\right)}{F\left[A_{0}\left(A_{0}-2 A_{1} F\right)+2 A_{1}\left(A_{0} F-2 A_{2}\right)\right]} .
\end{aligned}
$$

This means that, in the framework of Allen production function, the elasticity of the substitution of factors, in contrast to the Cobb-Douglas production function and other neoclassical functions, has a rather complex expression (12). It can be represented in terms of the marginal impact of production factors (7):

$$
\sigma_{L K}=\frac{M P_{L} M P_{K}}{K\left(A_{0} M P_{K}-2 A_{1} M P_{L}\right)}
$$

under conditions $K \neq 0, A_{0} \neq 2 A_{1} M R S_{L K}$.

\section{An analysis of the production process and the problem of constructing a model of economic growth}

Allen two-factor production function belongs to a group of substitutional functions, that is, it is assumed that the productive resources $K, L$ are to some extent interchangeable. This means that a certain amount of one production factor can be offset by the corresponding amount of another (formulas (9) - (11) with constant output $Y$.

And at zero the value of one of the production factors provided $A_{1}, A_{2}<0$, the elasticity of the substitution of the production function (1) goes to infinity (formula (5), that is, behaves like a linear function.

This property is called the assumption of non-zero replacement of resources. In other words, for Allen production function, a fair relation

$$
\begin{aligned}
& A_{0}\left(K+\Delta^{\prime}\right) L-A_{1}\left(K+\Delta^{\prime}\right)^{2}-A_{2} L^{2}= \\
& =A_{0} K\left(L+\Delta^{\prime \prime}\right)-A_{1} K^{2}-A_{2}\left(L+\Delta^{\prime \prime}\right)^{2},
\end{aligned}
$$

That is marginal products of capital $M P_{K}$ and labour $M P_{L}$ (7) within the framework of the production function (1) differ from zero, and the marginal rate of substitution of production factors $M R S_{L K}(11)$ exists in the form of a certain real non-reactive number.

Therefore, based on the rule we have developed for determining the optimal capital stock $F^{*}$, which maximizes production output $Y$. Given the total amount of capital expenditures by the equimarginal principle, one can find the value $F^{*}$ in the framework of Allen production function (Florin, 2011; Lemoine, Mazzi, MonperrusVeroni, \& Reynès, 2010). To this end, the marginal rate of substitution of factors $M R S_{L K}$ equate to unity:

$$
M R S_{L K}=\frac{A_{0} F-2 A_{2}}{A_{0}-2 A_{1} F}=1 .
$$

Where $F^{*}$ is equal to:

$$
F^{*}=\frac{A_{0}+2 A_{2}}{A_{0}+2 A_{1}} \text {. }
$$

It is clear that this requirement must be met $A_{0} \neq-2 A_{1}$. Consequently, when investing in factors $K$ and $L$ in the proportion (16), the production process, which is adequately described by the production function (1), will ensure the maximum output $Y_{M A X}$.

Expressing $K(L)$ from formula (16) and substituting into a production function (1), we find the maximum production output at the point of optimal capital stock on the condition of the adequacy of Allen function for the economic phenomenon being investigated:

$$
\begin{aligned}
& K=L \frac{A_{0}+2 A_{2}}{A_{0}+2 A_{1}}, \quad Y_{M A X}=A_{0} L^{2} \frac{A_{0}+2 A_{2}}{A_{0}+2 A_{1}}-A_{1} L^{2}\left(\frac{A_{0}+2 A_{2}}{A_{0}+2 A_{1}}\right)^{2}-A_{2} L^{2} ; \\
& L=K \frac{A_{0}+2 A_{1}}{A_{0}+2 A_{2}} Y_{M A X}=A_{0} K^{2} \frac{A_{0}+2 A_{1}}{A_{0}+2 A_{2}}-A_{1} K^{2}-A_{2} K^{2}\left(\frac{A_{0}+2 A_{1}}{A_{0}+2 A_{2}}\right)^{2} .
\end{aligned}
$$

Taking into account (16), as well as expressions $K$, $L$ from (17) we find the minimum total cost of capital $C_{M I N}=K+L$ for Allen production function in the event of a given production $Y$ and optimal asset management: 1) because of the specified labour costs $L$ :

$$
C_{M I N}=K+L=L\left(\frac{A_{0}+2 A_{2}}{A_{0}+2 A_{1}}+1\right)=2 L\left(\frac{A_{0}+A_{1}+A_{2}}{A_{0}+2 A_{1}}\right)
$$

2) because of the specified costs, sent to the main productive assets $K$ :

$$
C_{M I N}=L+K=K\left(\frac{A_{0}+2 A_{1}}{A_{0}+2 A_{2}}+1\right)=2 K\left(\frac{A_{0}+A_{1}+A_{2}}{A_{0}+2 A_{2}}\right) .
$$

Summarizing results of formulas (6) - (19), in Table 1, we present the main economic-mathematical parameters of Allen production function (1).

Equations (1) and (4) are usually used in the case of modelling the variation of empirical data in space, for example, when they are based on annual financial and statistical information for a group of enterprises. When the model is based on empirical data that varies in time (for example, one enterprise in a number of years), then it is necessary to use the Allen dynamic production function. In this case, the equation (1) takes the form:

$$
Y=A_{0} K L-A_{1} K^{2}-A_{2} L^{2}+\omega t,
$$

where $\omega-$ an average annual absolute increase of production $Y$ at the expense of all factors other than $K \&$ $L ; t$ - time factor $(t=1,2, \ldots, N)$.

The magnitude of the quantitative parameter $\omega$ reflects all those qualitative changes that occur in the economy and are not related to the factors of "basic 
Table 1

Basic economic and mathematical characteristics of Allen production function

\begin{tabular}{|c|c|c|}
\hline Indicator & $\mathrm{K}$ & $\mathrm{L}$ \\
\hline 1. Average return & $\frac{Y}{K}=A_{0} L-A_{1} K-A_{2} L\left(\frac{L}{K}\right)$ & $\frac{Y}{L}=A_{0} K-A_{1} K\left(\frac{K}{L}\right)-A_{2} L$ \\
\hline 2. Marginal return & $M P_{K}=A_{0} L-2 A_{1} K$ & $M P_{L}=A_{0} K-2 A_{2} L$ \\
\hline \multirow[b]{2}{*}{$\begin{array}{l}\text { 3. Elasticity of } \\
\text { product release, } \%\end{array}$} & $E_{-}=-A_{0} L-2 A_{1} K$ & \multirow{2}{*}{$E_{\mathrm{L}}=\frac{A_{0} K-2 A_{2} L}{A_{0} K-A_{1} K\left(\frac{K}{L}\right)-A_{2} L}$} \\
\hline & $A_{0} L-A_{1} K-A_{2} L\left(\frac{L}{K}\right)$ & \\
\hline $\begin{array}{l}\text { 4. The need for production } \\
\text { resources }\end{array}$ & $\begin{array}{l}K=\frac{-A_{0} L \pm \sqrt{D}}{2 A_{1}}, \partial e \\
D=\left(A_{0} L\right)^{2}-4 A_{1}\left(Y+A_{2} L^{2}\right)\end{array}$ & $\begin{array}{l}L=\frac{-A_{0} K \pm \sqrt{D}}{2 A_{2}}, \partial e \\
D=\left(A_{0} K\right)^{2}-4 A_{2}\left(Y+A_{1} K^{2}\right)\end{array}$ \\
\hline $\begin{array}{l}\text { 5. Replacement of factors } \\
\text { (capital stock) }\end{array}$ & $F=\frac{K}{L}$ & \\
\hline $\begin{array}{l}\text { 6. Marginal rate of } \\
\text { factors' replacement }\end{array}$ & $M R S_{L K}=\frac{A_{0} F-2 A_{2}}{A_{0}-2 A_{1} F}$ & \\
\hline $\begin{array}{l}\text { 7. Elasticity of } \\
\text { factors' replacement }\end{array}$ & $\sigma_{L K}=\frac{M P_{L} M P_{K}}{K\left(A_{0} M P_{K}-2 A_{1} M P_{L}\right)}$ & \\
\hline 8. Optimal capital stock & $F^{*}=\frac{A_{0}+2 A_{2}}{A_{0}+2 A_{1}}$ & \\
\hline $\begin{array}{l}\text { 9. Maximum issue } \\
\text { products given } \\
\text { total cost } \\
\text { capital and optimal } \\
\text { capital stock }\end{array}$ & $\begin{array}{l}Y_{M A X}=A_{0} K^{2} \frac{A_{0}+2 A_{1}}{A_{0}+2 A_{2}}- \\
-A_{1} K^{2}-A_{2} K^{2}\left(\frac{A_{0}+2 A_{1}}{A_{0}+2 A_{2}}\right)^{2}\end{array}$ & $\begin{array}{l}Y_{M A X}=A_{0} L^{2} \frac{A_{0}+2 A_{2}}{A_{0}+2 A_{1}}- \\
A_{1} L^{2}\left(\frac{A_{0}+2 A_{2}}{A_{0}+2 A_{1}}\right)^{2}-A_{2} L^{2}\end{array}$ \\
\hline $\begin{array}{l}\text { 10. Minimal total } \\
\text { capital expenditure at } \\
\text { given release } \\
\text { products and optimal } \\
\text { capital stock } \\
\end{array}$ & $C_{M I N}=2 K\left(\frac{A_{0}+A_{1}+A_{2}}{A_{0}+2 A_{2}}\right)$ & $C_{M I N}=2 L\left(\frac{A_{0}+A_{1}+A_{2}}{A_{0}+2 A_{1}}\right)$ \\
\hline
\end{tabular}

Source: own development

productive assets" and "labour". It characterizes the general economic conditions of reproduction at a specific production (in the enterprise, in the region, in the country) at a given time interval.

All unknown coefficients of regression $A_{0}, A_{1}, A_{2}$, $\omega$ of models (20) are determined similarly to the previous case - based on standard regression analysis programs. In both situations, the volume of the information base (sample size) should be 3-4 times more than the number of unknown parameters to be evaluated. That is, for the model (4), it is 9-12 points, for the model (20) - 12-16 observations.

\section{Allen production function as an instrument for assessing the economic efficiency of investment in production}

Certain scientific and practical interest acquires Allen production function as an instrument for assessing the economic efficiency of future investment in production.
Consider the effect of the values of the coefficients of the production function (1) on the value of the total future capital investment $C=K+L$. The main reason for this reasoning is that future profits $\mathrm{p}(K, L)$ should be a positive value:

$$
p(K, L)=Y-C=A_{0} K L-A_{1} K^{2}-A_{2} L^{2}-C>0 .
$$

In the opposite case, investments in a market economy lose all meaning. Immediately note that the values $K, L$ as a part of the overall future capital investment $C$ it is expedient to take in the ratio of an optimal capital stock (16):

$$
K=\frac{0,5 A_{0}+A_{2}}{A_{0}+A_{1}+A_{2}} \cdot C ; \quad L=\frac{0,5 A_{0}+A_{1}}{A_{0}+A_{1}+A_{2}} \cdot C .
$$

It is easy to verify that the costs of basic productive assets and labour (22) satisfy the ratio (16), and their sum equals investment $C$. Enter the following notation:

$$
\frac{0,5 A_{0}+A_{2}}{A_{0}+A_{1}+A_{2}}=S ; \frac{0,5 A_{0}+A_{1}}{A_{0}+A_{1}+A_{2}}=T .
$$


Then $K, L$ from the expression (22) are represented as follows: $K=S C, L=T C$. We will substitute them into inequality (21):

$$
p(K, L)=A_{0} S T C^{2}-A_{1} S^{2} C^{2}-A_{2} T^{2} C^{2}-C>0 .
$$

From the relation (24) follows:

$$
p(K, L)=C\left(A_{0} S T-A_{1} S^{2}-A_{2} T^{2}\right)>1 \text {. }
$$

So, future profits $\mathrm{p}(K, L)$ will be positive when the requirement is fulfilled:

$$
C>\left(A_{0} S T-A_{1} S^{2}-A_{2} T^{2}\right)^{-1} \text {. }
$$

The inequality (26) determines the lower boundary of the future investment $S$.

Thus, investing in production, which is adequately described by the production function (1), will be costeffective if the future investment $\mathrm{C}$ satisfies the following condition:

$$
C>\left(A_{0} S T-A_{1} S^{2}-A_{2} T^{2}\right)^{-1} \text {. }
$$

Consider now the case of applying the Allen dynamic production function (20). In this situation, it is possible to estimate the minimum payback period of the future investment. It is easy to show that, in order to obtain a positive return on investment, the payback period must satisfy the inequality:

$$
t>\frac{C}{\omega}\left(1-A_{0} S T C+A_{1} S^{2} C+A_{2} T^{2} C\right) .
$$

It is supposed that the production of additional products is carried out in conditions of optimal capital stock when capital investments are distributed in proportion (22).

We illustrate the procedure of construction, economic interpretation and practical use of Allen production function, according to the statistical reporting of the enterprise "X" for 2005-2015 (Table 2).

Table 2

Outgoing data for modelling the dependence of production output of enterprise " $X$ " from capital costs on basic production funds and pay

\begin{tabular}{|c|c|c|c|c|c|}
\hline Years & $\begin{array}{c}Y, \\
\text { thousand } \\
\text { UAN }\end{array}$ & $\begin{array}{c}K, \\
\text { thousand } \\
\text { UAN }\end{array}$ & $\begin{array}{c}L, \\
\text { thousand } \\
\text { UAN }\end{array}$ & $t$ & $K / L$ \\
\hline 2005 & 14820 & 13978 & 851 & 1 & 16,425 \\
\hline 2006 & 23439 & 14690 & 1401 & 2 & 10,485 \\
\hline 2007 & 40538 & 17644,5 & 2409 & 3 & 7,324 \\
\hline 2008 & 46790 & 23492,5 & 2839 & 4 & 8,275 \\
\hline 2009 & 42603 & 26834 & 3502 & 5 & 7,662 \\
\hline 2010 & 43214 & 16039 & 4913 & 6 & 3,265 \\
\hline 2011 & 53988 & 18121 & 7940 & 7 & 2,282 \\
\hline 2012 & 68049 & 18326 & 9202 & 8 & 1,992 \\
\hline 2013 & 67577 & 21624 & 9959 & 9 & 2,171 \\
\hline 2014 & 60321 & 23747 & 10591 & 10 & 2,242 \\
\hline 2015 & 56149 & 26084,5 & 12293 & 11 & 2,122 \\
\hline
\end{tabular}

Since the source data is presented in the form of time series, we will apply a dynamic model (20). As a result of calculations, the following equation was obtained:

$$
\begin{aligned}
& \mathrm{Y}=0,0010709 \mathrm{KL}-0,0001005 \mathrm{~K} 2- \\
& -0,0015433 \mathrm{~L} 2+10366,9983 \mathrm{t},
\end{aligned}
$$

where $Y$ - realized products of the enterprise, thousand UAH.

The Allen dynamic production function (29), built on 11 observations, was statistically reliable as a whole ( $F$ - Fisher's criterion 12.19 with a probability of error 0.005 ) and on individual coefficients according to Student's criterion (probability of error does not exceed $0.08)$. Determination factor $R^{2}=0,8905$ indicates that more than $89.6 \%$ of the time variation of the product sold is adequately described by the equation (29).

Although small but positive values of the coefficients $A_{1}, A_{2}$ indicate that with the growth of production factors $K, L$ the output of meat products in time gradually diminished. Model parameter $\omega$ shows the absolute annual growth of sales in the amount of 10366.99 thousand UAH that the enterprise " $X$ " received at the expense of all factors, except $K \& L$. The main of them was the growth of prices for products of the enterprise, especially in recent years.

By formula (16) we find the optimal capital stock at the enterprise for the study period of time:

$$
F^{*}=\frac{A_{0}+2 A_{2}}{A_{0}+2 A_{1}}=\frac{0,0010709+2 \times 0,0015433}{0,0010709+2 \times 0,0001005}=3,269 .
$$

If you look at the initial data of the enterprise " $\mathrm{X}$ ", then we can see that the actual capital stock in general exceeds the optimal. This means that the productive assets for enterprises " $\mathrm{X}$ " are in surplus. Find the average marginal rate of replacement of $M R S_{L K}$ resources at the enterprise for the entire study period:

$$
\begin{aligned}
& M R S_{L K}=\frac{A_{0} F-2 A_{2}}{A_{0}-2 A_{1} F}= \\
& =\frac{0,0010709 \times 3,347-2 \times 0,0015433}{0,0010709-2 \times 0,0001005 \times 3,347}=1,250 .
\end{aligned}
$$

Value $M R S_{L K}=1,25>1$ confirms the conclusion about the suboptimal capital stock at the initial stage (2005-2009) of the investigated period and the excess of capital invested in production funds for enterprises " $\mathrm{X}$ " in comparison with labour costs. Therefore, the question arises: what revenues from the sale of the enterprise " $\mathrm{X}$ " would have received, for example, in 2009, with the optimal capital stock of 3.269 and actual labour costs of 3502 thousand UAH? In answering this question, we will use the first of formulas (17), taking into account that the Allen dynamic production function with a plural $\omega t^{\prime}\left(t^{\prime}-\right.$ the number of the year corresponding to the research year):

$$
\begin{aligned}
& Y_{M A X}=L^{2}\left[A_{0} F^{*}-A_{1}\left(F^{*}\right)^{2}-A_{2}\right]+\omega t^{\prime}= \\
& =3502^{2}\left[0,0010709 \times 3,269-0,0001005 \times(3,269)^{2}-\right. \\
& -0,0015433]+10366,998 \times 5=62665,74 .
\end{aligned}
$$

Note that in 2009, the sale to enterprises " $\mathrm{X}$ " amounted to 42603 thousand UAH. Consequently, 
reserve for the growth of products sold at the expense of optimizing capital stock (primarily due to the sale of part of unused basic production assets) amounted to approximately $62666-42603=20063$ thousand UAH. In 2012, the sale to enterprises " $X$ " amounted to 68049 thousand UAH. Therefore, the reserve for the growth of products sold at the expense of optimization of capital stock (primarily due to the sale of part of unused basic production assets) amounted to approximately 157717 - $68049=89668$ thousand UAH. Similar calculations of hidden reserves of sales of the enterprise "X" can be made for all years of the period of nonoptimal capital stock.

\section{Conclusion}

Analysis of production based on the application of the usual and dynamic Allen production function, which adequately describes the economic object in conditions of production factors' growth and reduction of production, showed the necessity and relevance of their application. In turn, the use of the apparatus of production functions as a tool for analysing the economic efficiency of future investment in the enterprise production has a great potential for development.

However, when conducting an economic analysis and forecasting the development of production and investment, there is a problem of aggregating economic indicators for economic and mathematical modelling (Koval, V., Prymush, Y., \& Popova, V., 2017). The application of the Allen dynamic production function allows us to estimate the minimum payback period of the future investment. It is proved that the production of additional products is carried out under conditions of optimal capital stock when capital investments are distributed in a corresponding proportion and will ensure the maximum output of $Y_{\text {MAX }}$ products.

The obtained results provide the necessary basis for constructing economic growth models based on the quantitative expression of the volume of the product using the corresponding production function. The proposed apparatus of production functions remains relevant in the study of investment valuation since it serves as the optimal means for establishing a change in indicators of economic dynamics. On the basis of models of production functions, including Allen production function, the modelling of the dependence of the output of the enterprise on capital expenditures on the main productive assets and labour remuneration was performed.

As prospects for further scientific advances in this area, we see a more detailed study of the Allen dynamic production function, since it is suitable for modelling production at individual enterprises in the context of crisis phenomena characteristic of the modern Ukrainian economy.

\section{References:}

Borovskyi, D. N. (2008). Production functions and the problem of choice of the economic-mathematical model of the active element. Radioelectronic and computer systems, 1 (28): 172-177.

Chetyrkin, E.M., \& Klas, A. (Eds.) (1986). Theory and practice of statistical modeling of economic. M.: Finance and Statistics, 272.

Cobb, C. W. (1928). Douglas P. H. Theory of production. American Economic Review, Supplement, 18(1): $139-165$ p.

Debertin, D. L. (2012) Agricultural Production Economics. Amazon Createspace.

Florin, P. (2011). Some aspects of the translog production function estimation Romanian Journal of Economics, 32, 1(41): 131-150.

Griliches, Z., \& Mairesse, J. (1995). Production functions: the search for identification. Working Paper No.5067, National Bureau of Economic Research.

Hrabovetskyi, B. E. (2006). Production functions: theory, construction, use in production management. Vinnytsia: UNIVERSUM, 137.

Kleiner, H. B. (1986). Production functions: theory, methods, implementation. M. : Finance and Statistics, 239.

Koval, V., Prymush, Y., \& Popova, V. (2017). The Influence of the Enterprise Life Cycle on the Efficiency of Investment. Baltic Journal of Economic Studies, 3(5): 183-187. doi:10.30525/2256-0742/2017-3-5-183-187.

Lemoine, M., Mazzi, G. L., Monperrus-Veroni, P., \& Reynès, F. (2010). A new production function estimate of the euro area output gap. Journal of Forecasting, 29 (1-2): 29-53.

Lewin, Peter. (2000). Firms, Resources and Production Functions: The Relevance of the New Growth Economics for the Theory of the Firm. Retrieved from http:// citeseerx.ist.psu.edu

Perloff, J. M. (2014) Microeconomics. Chapter 7: Costs. Retrieved from: http://wps.aw.com/

Shumska, S. S. (2007a). Production Function in Economic Analysis: Theory and Practice of Use. Economic of Forecasting, 2: 138-153.

Shumska, S. S. (2007b). The instrument of production function in the exploration of the Ukrainian economy. Economic of forecasting, 4: 104-123. 
Solow, R. M. (1957). Technical Change and the Aggregate Production Function. The Review of Economics and Statistic, 39 (3): 312-320.

Turner, K., Lange, I., Lecca, P., \& Jung, Ha S. (2012), Econometric estimation of nested production functions and testing in a computable general equilibrium analysis of economy-wide rebound effects. Stirling Economics Discussion Paper 2012-08, Stirling Management School, University of Stirling. Retrieved from http://www.management.stir.ac.uk/research/economics/working-papers.

Yankovyi, V. O. (2017). Finding the optimum of the commodity producer in the framework of $\mathrm{N}$-factor production functions. Market Infrastructure, 7: 430-436. 